Vol.01/ No. 02

Pages: $111-121$

https://www.irojournals.com/iroiip/

DOI: https://doi.org/10.36548/jiip.2019.2.006

\title{
RGBD ANALYSIS FOR FINDING THE DIFFERENT STAGES OF MATURITY OF FRUITS IN FARMING
}

\author{
Dr. Abraham Chandy, \\ Professor, \\ Karunya University, \\ Coimbatore, India. \\ Email id: abrahamchandy@karunya.edu
}

\begin{abstract}
The agriculture being the major source of revenue for the people in the rural areas in a country like India many measures have been taken to improve the revenue of the farmers. The assessing the ripeness of the fruits is also one of the primary responsibilities of the farmer to fix the proper time to glean the fruits and taking them to the market. Computer vision and the image processing together remains as a key methodology in reducing the human labor and classifying the different stages of maturity is has become very prominent in examining the stages of the fruit growth. As the color seems to be the important feature to be observed in determining the different stages of the fruits maturity and color identification of the tropic fruits is difficult due to the various illuminations and the partial clogging up of the fruits. In order to identify maturity stage of the fruits the paper proposes a RGBD analysis to examine the stages of the fruits and identify the various stages of maturity.
\end{abstract}

Keywords: Fruit Farming, Maturity Stage, Image Processing, Computer Vision, Machine Learning Approaches, RGBD Analysis.

\section{INTRODUCTION}

In order to improve the yielding rate of the fruits in its season all over the world, and in turn increase the GDP of the agriculture, farmers from countries like India strive a lot and put in enormous labor to bring out a better yield, in the fruits with a maturity that is required and preferred in the market. The are several reasons that affect the yield of the fruits such as the climatic changes, rapidly urbanization, population ageing, shortage of labor and the increasing labor costs etc. In most cases the farmer's ignorance about the maturity of the fruits remains as the major reason that affects the yield rate [1-5].

ISSN: 2582- 4252 
Journal of Innovative Image Processing (JIIP) (2019)

Vol.01/ No. 02

Pages: $111-121$

https://www.irojournals.com/iroiip/

DOI: https://doi.org/10.36548/jiip.2019.2.006

Often farmer fails to notice the standard ripeness of the fruits such as its texture, shelf life, color and the sugar composition that is preferred by the consumer, the ripeness of the fruits has an impressive influence on the consumer approving resistance against the pathogens and the transporting to long distance [6-8].

In the early days the quality of the fruit was assessed by the humans, in spite of the hard labor and the long duration observation[9-10] put forth by the user, numerous of distractions in the daily routines and the other factors, caused numerous of errors in the estimation of the fruit ripeness.

So to minimize the failure rates in the observing the fruit growth and its quality assessment the fast, reliable and cost effective methods that were within the budget of the farmers were necessitated [11-12]. So the paper put forward the novel method to analyses the fruit maturity by involving the capsule network to identify the tropic fruits and utilized the density clustering and the depth filter to group the RGBD filtered images and further employs the fuzzy-rule based interference system to segment the fruits and the linear SVM to detect the maturity of the fruits.

\subsection{CONTRIBUTIONS OF THE PAPER}

To identify the fruit maturity, the different stages were distinguished into three stages as the (i) Premature, (ii) mature and (iii) over mature.

Capsule network employed differentiate the tropic fruits from the other types of objects found in the images.

The depth filter is engaged to determine the depth of the images acquired and the image segmentation is done using the fuzzy interference system.

Followed by the image segmentation the images are grouped using the density based clustering and classified using a linear support vector machine trained with the color, geometry and the gradient features of the fruits in the images.

\subsection{PAPER ORGANIZATION}

The paper is organized with the literature survey presenting the prevailing methods in the identifying the fruit maturity in the section 2 . The proposed RGBD analysis employing the trained capsule network, depth filters, fuzzy

ISSN: 2582- 4252 
Journal of Innovative Image Processing (JIIP) (2019)

Vol.01/ No. 02

Pages: $111-121$

https://www.irojournals.com/iroiip/

DOI: https://doi.org/10.36548/jiip.2019.2.006

interference system, density clusters and the linear support vector machine trained with the geometric, gradient and the color feature for ripe fruit detection in section 3. The results observed in the section 4 and the conclusion in the section 5 .

\section{LITERATURE SURVEY}

Nowadays the computer vision utilized in various methodologies is also engaged in the identifying the fruit ripening stage by segmenting the images of the fruits according to their features such as the color, sweetness, size etc. recently number of algorithms for better image processing have been utilized to identify the defects in the fruits the ripeness of the fruits, etc. some of the prevailing methods in identifying the process is listed below in the table. 1

ISSN: 2582- 4252 
Journal of Innovative Image Processing (JIIP) (2019)

Vol.01/ No. 02

Pages: 111-121

https://www.irojournals.com/iroiip/

DOI: https://doi.org/10.36548/jiip.2019.2.006

ISSN: 2582- 4252 
Journal of Innovative Image Processing (JIIP) (2019)

Vol.01/ No. 02

Pages: $111-121$

https://www.irojournals.com/iroiip/

DOI: https://doi.org/10.36548/jiip.2019.2.006

Table.1 Literature survey

\section{PROPOSED RGBD ANALYSIS FOR THE DETECTION OF THE FRUITS}

The RGB-D images were acquired from the fruit farm in a province in the Srinagar from the year 2016, 2017, and 2018 to 2019. The farm consisted of 75 rows and with 100 draining per row from which 50 rows were selected randomly. So an overall of 6000 images were acquired from the farm, the images contained both the tropic as well as the exotic fruits. The flow chart below in the figure.1 shows the procedure followed in detecting the fruit maturity.

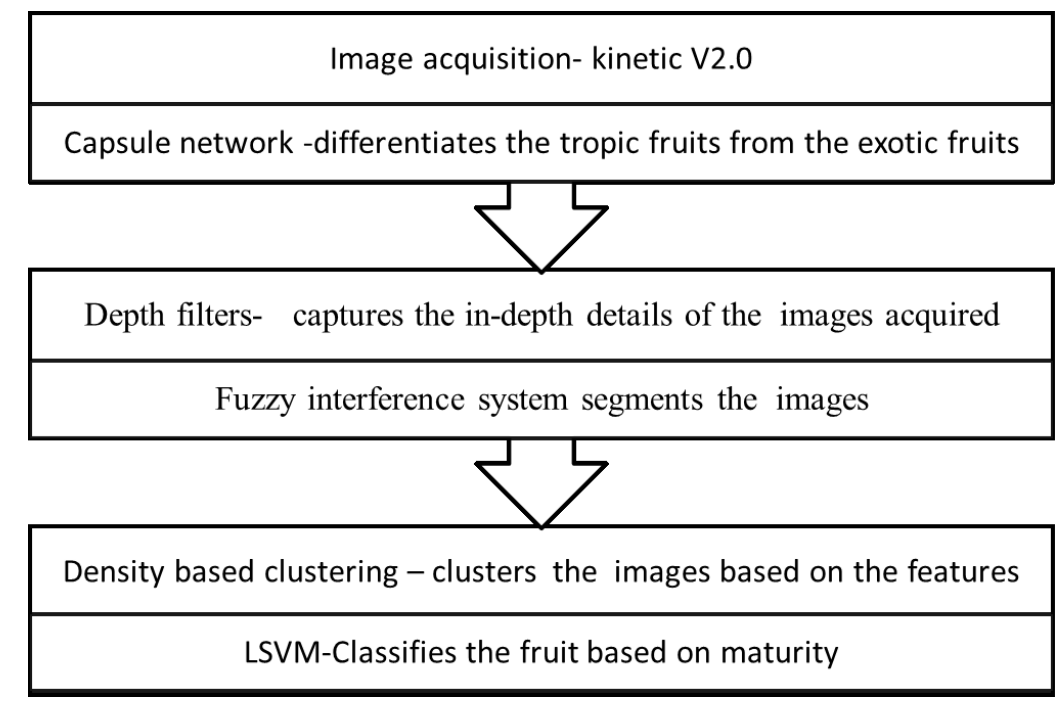

Fig. 1 Flow chart of Proposed Method

ISSN: 2582- 4252 
Journal of Innovative Image Processing (JIIP) (2019)

Vol.01/ No. 02

Pages: 111-121

https://www.irojournals.com/iroiip/

DOI: https://doi.org/10.36548/jiip.2019.2.006

Kinetic V2 sensor that is built with the RGB and infrared camera acquires the RGB-D images; it produces the RGB images with the pixels $1920 * 1080$ and the depth of the image by $512 * 424$, pixels continuously with 30 frames per second. The sensor was located at $50 \mathrm{~mm}$ from the fruit trees in the farm; the end to end trained capsule network was utilized in the method to recognize the images of the fruits from the images acquired the equation (1) was framed in this regard.

$$
\text { Prob }=\lambda \operatorname{prob}_{r}+(1-\lambda) \text { prob }_{\text {detecting }}
$$

Where, the Prob is the probability in identifying the fruit, the resulting probability is indicated as the $p r o b_{r}$ and the probability of results obtained in identifying the fruits is denoted as theprob detecting .

The supra cap series depth filters with the normal retention of .4 to .8 is used in the proposed method to gather the in depth details of the images acquired, The filter estimates the RGB-D image, RGB values and the 3D co-ordinate of the image pixels. The 3D co-ordinate and the RGB value for the each pixel $\left(P_{i}\right)$ is calculated using the following equation (2)

$$
P_{i}=m_{i} \cdot n_{i} \cdot q_{i}
$$

Where, $m_{i}=$ image depth $*$ image coordinates of every pixel, $n_{i}$ and $q_{i}$ represents the intrinsic parameters of the IR camera. The threshold values set for the identifying the appropriate depth values and the fuzzy interference system was utilized to segment the image removing the unimportant point acquired and based on the color of the fruits. Further the density based clustering employed gets in the RGB-D images and selects the cluster center randomly and computes the features of the fruits in terms of size, texture and color and groups them separately to train the linear SVM, the threshold values were set for each features and the clusters were framed based on the threshold values, The table. 2 below shows the threshold values set for the fruits features.

ISSN: 2582- 4252 
Journal of Innovative Image Processing (JIIP) (2019)

Vol.01/ No. 02

Pages: $111-121$

https://www.irojournals.com/iroiip/

DOI: https://doi.org/10.36548/jiip.2019.2.006

\begin{tabular}{|c|c|}
\hline Fruit Features & $\begin{array}{c}\text { Threshold values } \\
\text { (percent) }\end{array}$ \\
\hline Size & $2-1 / 2$ inches or 100 grams \\
\hline Color & 66 \\
\hline Sweetness & 78 \\
\hline Texture & 50 \\
\hline Damage & Less than 10 \\
\hline
\end{tabular}

Table.2 Fruit Features

Based on the requirement the linear SVM is trained based on the geometry, gradient and the color of the prematured matured and the over matured fruits. The clustered images half of the images are used in the training and half is utilized for the testing from each group, based on the training provided, the LSVM classifies the remaining images as mature, premature and over matured fruit.

\section{RESULTS}

The proposed method evaluated in the MATLAB to verify the accuracy in the prediction and the validation. the figure. 2 below shows the image acquired from the farm.

ISSN: 2582- 4252 
Journal of Innovative Image Processing (JIIP) (2019)

Vol.01/ No. 02

Pages: $111-121$

https://www.irojournals.com/iroiip/

DOI: https://doi.org/10.36548/jiip.2019.2.006
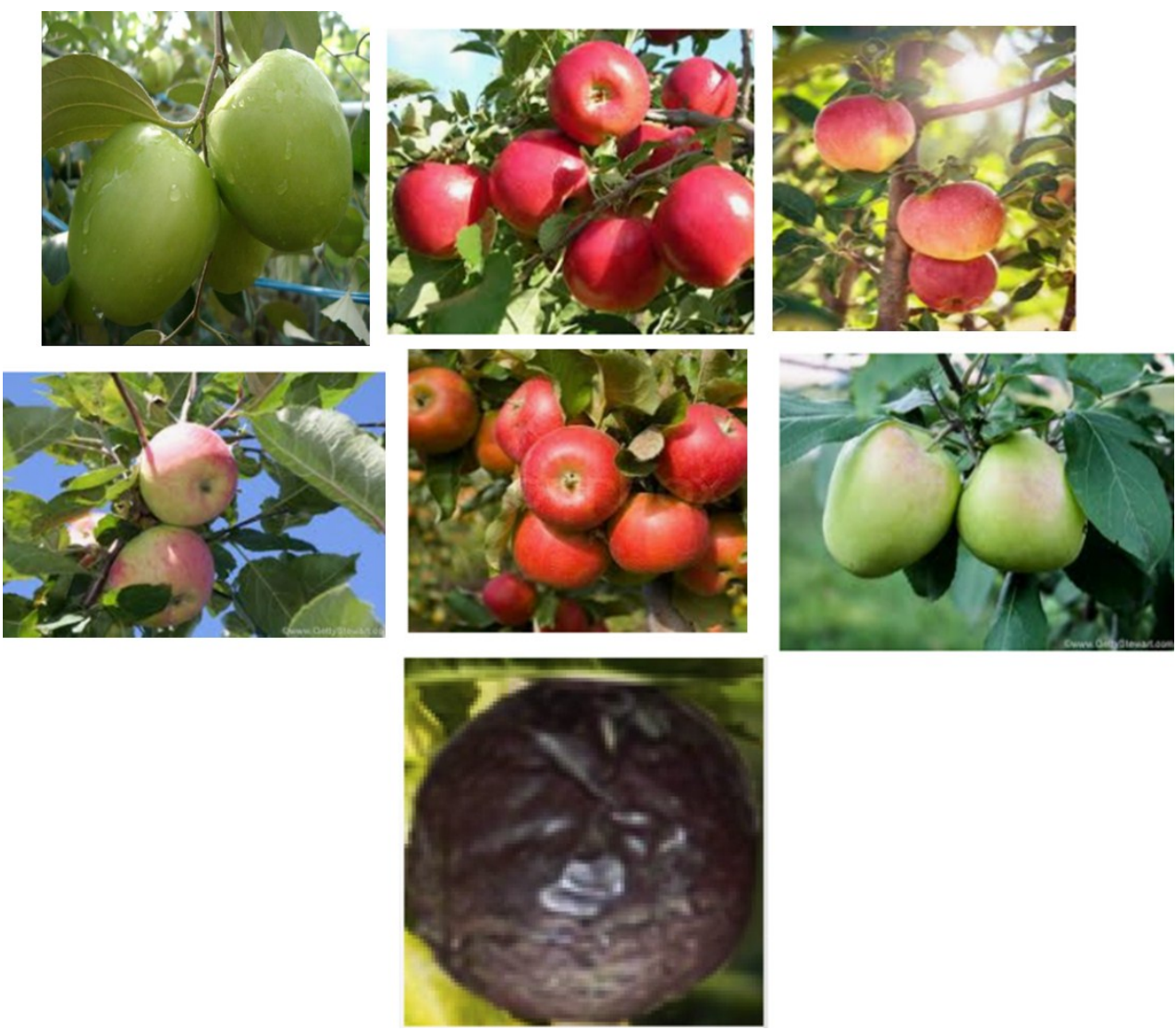

The images acquired are tested with the LSVM to identify the maturity of the fruits. The table. 3 below provides the training and validation accuracy, the true positives the false positives precision, recall and the F1 Sore. The some of the existing methods such as the RVM, KNN and ANN where compared with the proposed method and was found that the proposed method shows higher accuracy in classification than the prevailing.

ISSN: 2582- 4252 
Journal of Innovative Image Processing (JIIP) (2019)

Vol.01/ No. 02

Pages: 111-121

https://www.irojournals.com/iroiip/

DOI: https://doi.org/10.36548/jiip.2019.2.006

\begin{tabular}{|l|l|l|l|l|l|l|l|l|l|}
\hline Method & $\begin{array}{l}\text { Numb } \\
\text { er of } \\
\text { fruits }\end{array}$ & $\begin{array}{l}\text { Total } \\
\text { numb } \\
\text { er of } \\
\text { image } \\
\text { s }\end{array}$ & $\begin{array}{l}\text { True } \\
\text { positive }\end{array}$ & $\begin{array}{l}\text { False } \\
\text { positive }\end{array}$ & Precision & Recall & $\begin{array}{l}\text { F1 } \\
\text { score }\end{array}$ & $\begin{array}{l}\text { Training } \\
\text { accuracy }\end{array}$ & $\begin{array}{l}\text { Testing } \\
\text { Accuracy }\end{array}$ \\
\hline KNN & 750 & 200 & 600 & 35 & .6756 & .5467 & .612 & $78 \%$ & $75 \%$ \\
\hline ANN & 750 & 200 & 550 & 20 & .8354 & .4563 & .667 & $85 \%$ & $80 \%$ \\
\hline RVM & 750 & 200 & 406 & 11 & .7564 & .3456 & .659 & $67 \%$ & $64 \%$ \\
\hline Propose & 750 & 200 & 745 & 5 & .9945 & .8745 & .973 & $95 \%$ & $93 \%$ \\
\hline d & & & & & & & & & \\
\hline
\end{tabular}

\section{CONCLUSION}

The proposed method helps in achieving the standard maturity level that is suitable for importing by employing the novel method to analyze the fruit maturity by involving the capsule network to identify the tropic fruits and utilizes the density clustering and the depth filter to group the RGBD filtered images and further employs the fuzzy-rule based interference system to segment the fruits and the linear SVM to detect the maturity of the fruits. The result obtained shows the $95 \%$ training and the $93 \%$ testing accuracy compared to the prevailing KNN, ANN and the RVM.

\section{References}

[1] Raj, Jennifer S., and J. Vijitha Ananthi. "AUTOMATION USING IOT IN GREENHOUSE ENVIRONMENT." Journal of Information Technology 1, no. 01 (2019): 38-47.

[2] Jimenez, A. R., R. Ceres, and Jose L. Pons. "A survey of computer vision methods for locating fruit on trees." Transactions of the ASAE 43, no. 6 (2000): 1911. 
Journal of Innovative Image Processing (JIIP) (2019)

Vol.01/ No. 02

Pages: $111-121$

https://www.irojournals.com/iroiip/

DOI: https://doi.org/10.36548/jiip.2019.2.006

[3] Vijayakumar, T. "COMPARATIVE STUDY OF CAPSULE NEURAL NETWORK IN VARIOUS APPLICATIONS." Journal of Artificial Intelligence 1, no. 01 (2019): 19-27.

[4] Rahimunnisa, K. "HYBRIDIZED GENETIC-SIMULATED ANNEALING ALGORITHM FOR PERFORMANCE OPTIMIZATION IN WIRELESS ADHOC NETWORK." Journal of Soft Computing Paradigm (JSCP) 1, no. 01 (2019): 1-13.

[5] Jacob, I. Jeena. "CAPSULE NETWORK BASED BIOMETRIC RECOGNITION SYSTEM." Journal of Artificial Intelligence 1, no. 02 (2019): 83-94.

[6] Koresh, Mr H. James Deva. "COMPUTER VISION BASED TRAFFIC SIGN SENSING FOR SMART TRANSPORT." Journal of Innovative Image Processing (JIIP) 1, no. 01 (2019): 11-19.

[7] Bashar, Abul. "SURVEY ON EVOLVING DEEP LEARNING NEURAL NETWORK ARCHITECTURES." Journal of Artificial Intelligence 1, no. 02 (2019): 73-82.

[8] Anguraj, Dinesh Kumar, and S. Smys. "Trust-based intrusion detection and clustering approach for wireless body area networks." Wireless Personal Communications 104, no. 1 (2019): 1-20.

[9] Sathesh, A. "PERFORMANCE ANALYSIS OF GRANULAR COMPUTING MODEL IN SOFT COMPUTING PARADIGM FOR MONITORING OF FETAL ECHOCARDIOGRAPHY." Journal of Soft Computing Paradigm (JSCP) 1, no. 01 (2019): 14-23.

[10] Raj, Jennifer S., and J. Vijitha Ananthi. "RECURRENT NEURAL NETWORKS AND NONLINEAR PREDICTION IN SUPPORT VECTOR MACHINES." Journal of Soft Computing Paradigm (JSCP) 1, no. 01 (2019): 33-40.

[11] Joseph, S. Iwin Thanakumar. "SURVEY OF DATA MINING ALGORITHM'S FOR INTELLIGENT COMPUTING SYSTEM." Journal of trends in Computer Science and Smart technology (TCSST) 1, no. 01 (2019): 14-24.

[12] Raj, Jennifer S. "A COMPREHENSIVE SURVEY ON THE COMPUTATIONAL INTELLIGENCE TECHNIQUES AND ITS APPLICATIONS." Journal of ISMAC 1, no. 03 (2019): 147-159.

[13] Li, Bairong, Yan Long, and Huaibo Song. "Detection of green apples in natural scenes based on saliency theory and Gaussian curve fitting." International Journal of Agricultural and Biological Engineering 11, no. 1 (2018): 192-198.

[14] Tan, Kezhu, Won Suk Lee, Hao Gan, and Shuwen Wang. "Recognising blueberry fruit of different maturity using histogram oriented gradients and colour features in outdoor scenes." Biosystems engineering 176 (2018): 59-72.

ISSN: 2582- 4252 
Journal of Innovative Image Processing (JIIP) (2019)

Vol.01/ No. 02

Pages: $111-121$

https://www.irojournals.com/iroiip/

DOI: https://doi.org/10.36548/jiip.2019.2.006

[15] UluiŞik, Selman, Fikret Yildiz, and Ahmet Turan Özdemİr. "Image processing based machine vision system for tomato volume estimation." In 2018 Electric Electronics, Computer Science, Biomedical Engineerings' Meeting (EBBT), pp. 1-4. IEEE, 2018.

[16] Taofik, A., N. Ismail, Y. A. Gerhana, K. Komarujaman, and Muhammad Ali Ramdhani. "Design of Smart System to Detect Ripeness of Tomato and Chili with New Approach in Data Acquisition." In IOP Conference Series: Materials Science and Engineering, vol. 288, no. 1, p. 012018. IOP Publishing, 2018.

[17] Pereira, Luiz Fernando Santos, Sylvio Barbon Jr, Nektarios A. Valous, and Douglas Fernandes Barbin. "Predicting the ripening of papaya fruit with digital imaging and random forests." Computers and electronics in agriculture 145 (2018): 76-82.

[18] Wan, Peng, Arash Toudeshki, Hequn Tan, and Reza Ehsani. "A methodology for fresh tomato maturity detection using computer vision." Computers and Electronics in Agriculture 146 (2018): 4350.

[19] Zhang, Yan, Jian Lian, Mingqu Fan, and Yuanjie Zheng. "Deep indicator for fine-grained classification of banana's ripening stages." EURASIP Journal on Image and Video Processing 2018, no. 1 (2018): 1-10.

[20] Kumar, Arun, Vijay S. Rajpurohit, and Bhairu J. Jirage. "Pomegranate fruit quality assessment using machine intelligence and wavelet features." Journal of Horticultural Research 26, no. 1 (2018): 53-60.

[21] Mim, Farjana Sultana, Syed Md Galib, Md Fakhrul Hasan, and Sanjida Akther Jerin. "Automatic detection of mango ripening stages-An application of information technology to botany." Scientia Horticulturae 237 (2018): 156-163.

[22] Tu, Shuqin, Yueju Xue, Chan Zheng, Yu Qi, Hua Wan, and Liang Mao. "Detection of passion fruits and maturity classification using Red-Green-Blue Depth images." Biosystems engineering 175 (2018): $156-167$.

ISSN: 2582- 4252 